\title{
Strategies to Minimize Tunneled Hemodialysis Catheter Use
}

\author{
Arif Asif Donna Merrill Carlos Leon Renee Ellis Phillip Pennell \\ Section of Interventional Nephrology, Division of Nephrology, University of Miami Miller School of Medicine, \\ Miami, Fla., USA
}

\section{Key Words}

Early fistula failure $\cdot$ Fistula thrombosis $\cdot$ Peritoneal dialysis $\cdot$ Interventional nephrology

\begin{abstract}
While the use of arteriovenous grafts has recently declined, there has been an astronomical increase in hemodialysis patients dialyzing with tunneled dialysis catheters (TDCs). Recent data have indicated that over $70 \%$ of the patients with end-stage renal disease initiate dialysis with a catheter. Additionally, up to $27 \%$ of the end-stage renal disease patients in the US are using TDCs as their permanent access, with placement rates having doubled since 1996. Although most modern catheters claim to provide adequate blood flow for dialysis, they are associated with the highest incidence of complications, morbidity and mortality when compared with other types of vascular access. It is for these reasons that the National Kidney Foundation Dialysis Outcomes Quality Initiative guideline 30 as well as the Fistula First Change Concept 7 emphasize limiting the use of catheters and fostering the creation of arteriovenous fistulae. Early referral has clearly been shown to minimize the use of TDCs and maximize fistulae. This report focuses on the role of additional measures that minimize TDC use, such as dialysis modality presentation and peritoneal dialysis, vascular access education, preoperative vascular mapping and salvage of early failure and thrombosed fistulae.
\end{abstract}

Copyright (C) 2006 S. Karger AG, Basel

\section{KARGER}

Fax +4161306 1234

E-Mail karger@karger.ch

www.karger.com
(C) 2006 S. Karger AG, Basel

0253-5068/06/0241-0090\$23.50/0

Accessible online at: www.karger.com/bpu

\section{Introduction}

It is a well-known fact that the highest morbidity and mortality exists in chronic hemodialysis patients dialyzing with tunneled dialysis catheters (TDCs) when compared with arteriovenous fistulae (AVFs) and arteriovenous grafts (AVGs). In addition, TDCs are associated with lower blood flows, increased incidence of local and systemic infection, development of central venous stenosis and frequent episodes of thrombosis. It is for these reasons that both the Fistula First Project and the National Kidney Foundation Dialysis Outcomes Quality Initiative (NKF-DOQI) guidelines for vascular access discourage the use of TDCs as long-term access for hemodialysis $[1,2]$. Although the NKF-DOQI guideline 30 states that less than $10 \%$ of the chronic dialysis patients should be maintained on TDCs [3], recent data have emphasized that up to $27 \%$ of the end-stage renal disease (ESRD) patients in the US are using TDCs as their permanent access $[4,5]$. Of particular concern is the fact that the use of TDCs as permanent dialysis access is steadily on the rise, with placement rates having doubled since 1996 [4]. This practice pattern of overutilization of tunneled catheters dooms us to failure in minimizing vascular access-related morbidity and mortality and reaching the goal of maximizing AVFs unless strategies to limit TDC use are formulated and implemented.

An ideal clinical pathway for avoiding, or minimizing, the use of TDCs would involve early identification of patients with chronic kidney disease (CKD), and secondly,

Assoc. Prof. Arif Asif, MD

Interventional Nephrology, University of Miami Miller School of Medicine 1600 NW 10th Ave (R 7168)

Miami, FL 33136 (USA)

Tel. +1 305243 3583, Fax +1 305243 3506, E-Mail aasif@med.miami.edu 
early referral to nephrologists, with progressively more intense involvement in medical management as CKD progresses to end stage. Indeed, early referral increases the likelihood of receiving an AVF and decreases the insertion of a TDC. This article presents some of the additional strategies that can have a positive impact on reducing the recent catheter epidemic.

\section{Modality Presentation and Peritoneal Dialysis}

Incident hemodialysis patients are either referred by nephrologists or are arbitrarily defined as 'catastrophic starts', meaning those patients who have not received care from a nephrologist during the 3 months immediately prior to initiating permanent renal replacement therapy. Traditionally, catastrophic-start patients are generally consigned to hemodialysis and, by default, receive a tunneled hemodialysis catheter. Although peritoneal dialysis (PD) offers a variety of advantages (including a slow continuous daily home dialysis, preservation of residual renal function, improved middle molecule clearance and fluid and blood pressure control, cost-effectiveness, reduced mortality, and better quality of life), this type of renal replacement therapy remains largely ignored [6]. Recent data have demonstrated that more that $50 \%$ of patients with ESRD who are informed about ESRD treatment options prefer and request PD as the modality of choice for renal replacement therapy [7-11]. In contrast, only $12 \%$ are receiving this type of dialysis therapy [4]. In this context, dialysis modality presentation and $\mathrm{PD}$ become a viable option to minimize TDCs.

The catastrophic-start patients also need to be educated about ESRD treatment options as soon as possible. In our experience, the informed catastrophic patient will often elect PD [12]. Frequently, we have found that it is possible to stabilize these patients, place a PD catheter, initiate permanent renal replacement therapy by means of PD and completely avoid even short-term outpatient hemodialysis using TDCs. Occasionally, stabilizing the hospitalized catastrophic patient may require acute hemodialysis treatments by means of a temporary catheter with subsequent discharge to initiate outpatient PD. In a recent analysis [12], 35 catastrophic-start patients were identified and received in-hospital education regarding dialysis modality presentation at our center. Of these, 11 (29\%) chose PD as a long-term dialysis modality. PD catheter was inserted in $8(73 \%)$ of 11 patients during the initial admission. The remaining 3 received a PD catheter on an outpatient basis. Nine of 11 patients needed a tunneled catheter for a few weeks only, while in the other 2 patients, TDC insertion was avoided altogether.

Data have indicated that survival of a tunneled PD catheter is far superior to that of a tunneled hemodialysis catheter. In one study, Gadallah et al. [13] demonstrated catheter survival of 76,63 and $51 \%$ at 1,2 and 3 years, respectively. Other investigators have also demonstrated excellent PD catheter survival [14]. These survival rates are far superior to tunneled hemodialysis catheter and, in fact, approach those of an AVF [1]. In addition, catheterrelated infections are exceedingly frequent with tunneled hemodialysis catheters $[15,16]$. PD, PD catheter survival and infection considerations must be entertained and applied as a strategy to limit TDC use in patients with ESRD.

\section{Vascular Access Counseling and Preoperative Mapping}

Vascular access education is one of the most powerful tools to help patients choose the best access for dialysis. Late referral does not mean that the patient can no longer have a fistula. Even if referred late, education regarding vascular access types and their associated complications, including the risk of morbidity and mortality, must be provided to patients who present to dialysis units with TDCs. Local and systemic infectious complications, catheter-related central vein stenoses and thromboses with consequent preclusion of future arteriovenous access creation in the upper extremities, the impact of low catheter flows on dialysis adequacy, and the increased overall death rate should be specifically highlighted for TDCs. Patients must be able to understand that an AVF is the best available access and has the lowest incidence of complications. Additionally, patient survival with an AVF must be emphasized. Patients should be educated and encouraged to request the creation of an AVF at their appointment with the surgeon $[1,2]$.

The strategy to minimize the use of TDCs is doing everything possible to maximize the possibility of placing fistulae. All patients identified with CKD and likely to progress to ESRD must have planful, programmatic preservation of veins for future arteriovenous access placement, as recommended by the NKF-K/DOQI guidelines [1]. Accordingly, arm veins should not be used for venipuncture or for intravenous catheters. Instead, veins on the dorsum of the hand should be used. Due to the risk of central vein thrombosis that would preclude future ac- 
cess placement in the ipsilateral arm, no catheters of any type should ever be placed in subclavian veins. Patients should be informed of these guidelines.

One of the most important aspects of vascular access education is to demonstrate the importance and techniques of vascular mapping prior to any surgical procedures. Data have confirmed that physical examination may not be adequate to demonstrate either the presence or absence of suitable veins for creation of an AVF [17, 18]. Vascular evaluation using Doppler ultrasound as well as venography must be emphasized. The impact of vascular mapping on limiting catheter use and maximizing fistulae should be discussed with TDC patients. Allon et al. [17] documented a dramatic increase in AVF creation when preoperative vascular mapping using sonography was employed compared with the traditional physical examination approach (preoperative physical examination $34 \%$, preoperative sonographic vascular mapping 64\%; $\mathrm{p}<0.001)$. Indeed, using the preoperative mapping approach, these investigators demonstrated a doubling of the patients dialyzing successfully with a fistula (preoperative physical examination $16 \%$, preoperative sonographic vascular mapping 34\%; $p<0.001$ ) [13]. In another study, Silva et al. [18] documented a significant improvement in AVF creation (from 14 to 63\%), a reduction in AVG placement (from 62 to 30\%) and, most importantly, a reduction in tunneled hemodialysis catheter insertion (from 24 to 7\%) when preoperative mapping of the arteries and veins was performed using Doppler duplex ultrasonography.

The value of vascular education and mapping in fostering the creation of AVFs and minimizing catheter use has been illustrated by a recent prospective study [19]. Among 86 patients consigned to TDCs, vascular mapping demonstrated that $94 \%$ with no prior arteriovenous accesses (64 of 66) had suitable veins for arteriovenous access placement and $90 \%$ with previously failed arteriovenous accesses (18 of 20) had suitable veins as well, all basilic veins in the latter cases. Fistulae were created in $94 \%$ of those patients who agreed to proceed to vascular access surgery (68 of 72 patients), the other 4 patients having required AVG placement. Of note, a significant reduction in catheter use from 34 to $14 \%$ was observed in this study. These findings clearly demonstrate the value of patient education and vascular mapping in detecting vessels suitable for arteriovenous access placement, even in patients previously consigned to percutaneous catheters because of prior vascular access failures. The most striking outcome of this experience was that AVFs comprised $94 \%$ of the arteriovenous accesses created. In- deed, these results virtually mandate the application of vascular access education and mapping to place an AVF in every patient dialyzing with a percutaneous catheter.

\section{Salvage of Early Failure and Failed AVF}

A significant number (28-53\%) of AVFs do not adequately develop and fail to sustain dialysis therapy [17, 19-22]. Often, renal physicians and surgeons wait for up to 6 months and even longer hoping that the fistula will eventually grow to support dialysis before declaring that the AVF has failed. In the interim, if dialysis is needed, the patient is subjected to a tunneled catheter and thereby exposed to the morbidity and mortality risks associated with the use of catheters. In general, a blood flow of $500 \mathrm{ml} / \mathrm{min}$ and a diameter of at least $4 \mathrm{~mm}$ are needed for a fistula to be adequate to support dialysis therapy [23]. Recent data have emphasized that in most successful fistulae, these parameters are met within 4-6 weeks of fistula creation [23-30]. Most importantly, commonly encountered problems (stenosis and accessory veins) underlying early fistula failure can be easily diagnosed, and a great majority of fistulae with early failure can be successfully salvaged by percutaneous interventions and become available for dialysis, thus minimizing reliance on TDCs [19, 31].

Multiple studies have demonstrated successful salvage of AVFs with early failure [19, 31, 32]. Recently, Beathard et al. [31] provided invaluable information on how to improve the function of an AVF that is not developing properly. In this prospective observational study, 100 patients with early failure underwent evaluation and treatment at six free-standing outpatient vascular access centers. Vascular stenosis and the presence of a significant accessory vein (an accessory vein is described as a branch coming off the main venous channel that comprised the fistula) alone or in combination were found to be the culprits. Venous stenosis was present in $78 \%$ of the cases. A majority of these lesions (48\%) were found to be close to the anastomosis (juxta-anastomotic lesion). A significant accessory vein was present in $46 \%$ of the cases. Percutaneous balloon angioplasty and accessory vein obliteration techniques were used to salvage the failed fistulae. The success rate of angioplasty was $98 \%$ and of vein obliteration $100 \%$. After intervention, it was possible to initiate dialysis using the fistula in $92 \%$ of the cases. Actuarial life table analysis showed that $84 \%$ of fistulae were functional at 3 months, $72 \%$ at 6 months and $68 \%$ at 12 months. 
Thrombosis leading to access failure is a major issue. It often causes unnecessary hospitalization, missed dialysis and can expose the patient to the insertion of tunneled hemodialysis catheter. Ideally, this complication should be managed rapidly, under local anesthesia and on an outpatient basis. Recent data have clearly shown that access thrombectomy can be achieved successfully and safely at many centers on an outpatient basis, thereby avoiding hospitalization or insertion of a catheter to dialyze the patient [33]. Although thrombectomy of AVGs is routinely performed, thrombosis of AVFs has generally been believed to cause irrecoverable fistula loss [34]. The fallacy of this opinion has been demonstrated by multiple reports [33, 35-38]. However, the thrombectomy procedure for an AVF is somewhat different than for a clotted $\mathrm{AVG}$ in that the procedure for a graft can be standardized to a greater degree. In contrast, the AVF procedure has to be individualized in each case. The long-term graft survival rates after thrombosis of an AVG are disappointingly low, ranging from 11 to $36 \%$ at a 6-month follow-up, regardless of whether endovascular or surgical techniques were utilized [39-41]. In contrast, thrombectomy of a fistula is rewarded by excellent outcomes. Initial success exceeding $80 \%$ combined with primary patency rates ranging from 50 to over $70 \%$ at 6 months $[33,35-38]$ is compelling evidence to attempt fistula thrombectomy instead of consigning an AVF patient to a tunneled hemodialysis catheter.

\section{Conclusion}

Dialysis modality presentation, PD, vascular access education, preservation of extremity veins, preoperative vascular mapping, timely salvage of early-failure and thrombosed fistulae are all viable options. In order to limit catheter use, and the associated risks of morbidity and mortality, these interventions must be routinely exercised.

\section{References}

1 NKF-K/DOQI Clinical Practice Guidelines for Vascular Access: update 2000. Am J Kidney Dis 2001;37(suppl 1):S137-S181.

$\checkmark 2$ Spergel L, Rowland J, Beasley C: Fistula first: an update for renal providers. Nephrol News Issues 2004; 18:88-90.

3 NKF-K/DOQI Clinical Practice Guidelines for Vascular Access: guideline 30. Update 2000. Am J Kidney Dis 2001;37(suppl 1): S170.

4 US Renal Data System: USRDS 2002 Annual Data Report. Bethesda, National Institutes of Health, National Institute of Diabetes and Digestive and Kidney Diseases, 2002, chapt 4.

52003 annual report: ESRD clinical performance measures project. Am J Kidney Dis 2004;44(suppl 2):S1-S92.

-6 Gokal R, Blake PG, Passlick-Deetjen J, Schaub TP, Prichard S, Burkart JM: What is the evidence that peritoneal dialysis is underutilized as an ESRD therapy? Semin Dial 2002;15: 149-150.

7 Schreiber MJ, Middleton JP, Mujais S, Villano $\mathrm{R}$, Owen D: Outcome of dialysis modality utilization after thorough patient education. J Am Soc Nephrol 2001;12:A1254.

8 Golper TA, Vonesh EF, Wolfson M, Baudoin M, Schreiber MJ: The impact of pre-ESRD education on dialysis modality selection. J Am Soc Nephrol 2000;11:1233A.

-9 Prichard S: Treatment modality selection in 150 consecutive patients starting ESRD therapy. Perit Dial Int 1996;16:69.
10 Golper TA: Preliminary results from a national pre-ESRD education program. Am J Kidney Dis 2000; 11:A1223.

11 Shabass B, Vonesh EF, Wolfson M, Baudoin M, Mujais S: The impact of pre-ESRD education on dialysis modality selection among African Americans. J Am Soc Nephrol 2000;11 A1280.

12 Asif A, Byers P, Gadalean F, Roth D: Peritoneal dialysis underutilization: the impact of an interventional nephrology peritoneal dialysis access program. Semin Dial 2003;16:266271.

13 Gadallah MF, Pervez A, EI-Shahawy MA, Sorrells D, Zibari G, McDonald J, Work J: Peritoneoscopic versus surgical placement of peritoneal dialysis catheters: a prospective randomized study on outcome. Am J Kidney Dis 1999;33:118-122.

14 Pastan S, Gassensmith C, Manatunga AK, Copley JB, Smith EJ, Hamburger RJ: Prospective comparison of peritoneoscopic and surgical implantation of CAPD catheters. ASAIO Trans 1991;37:M154-M156.

15 Dhingra RK, Young EW, Hulbert-Shearon TE, et al: Type of vascular access and mortality in US hemodialysis patients. Kidney Int 2001;60: 1443-1451.

16 Pastan S, Soucie JM, McClellan WM: Vascular access and increased risk of death among hemodialysis patients. Kidney Int 2002;62:620 626 .
17 Allon M, Lockhart ME, Lilly RZ, Gallichio MH, Young CJ, Barker J, Deierhoi MH, Robbin ML: Effect of preoperative sonographic mapping on vascular access outcomes in hemodialysis patients. Kidney Int 2001;60:20132020.

18 Silva MB Jr, Hobson RW 2nd, Pappas PJ, et al: A strategy for increasing use of autogenous hemodialysis access procedures: impact of preoperative noninvasive evaluation. J Vasc Surg 1998;27:302-307.

19 Asif A, Cherla G, Merrill D, Cipleu CD, Briones P, Pennell P: Conversion of tunneled hemodialysis catheter-consigned patients to arteriovenous fistula. Kidney Int 2005;67: 2399-2407.

20 Palder SB, Kirkman RL, Whittemore AD, Hakim RM, Lazarus JM, Tilney NL: Vascular access for hemodialysis. Patency rates and results of revision. Ann Surg 1985;202:235-239.

21 Miller PE, Tolwani A, Luscy CP, Deierhoi MH, Bailey R, Redden DT, Allon M: Predictors of adequacy of arteriovenous fistulas in hemodialysis patients. Kidney Int 1999;56: 275-280.

22 Won T, Jang JW, Lee S, Han JJ, Park YS, Ahn $\mathrm{JH}$ : Effects of intraoperative blood flow on the early patency of radiocephalic fistulas. Ann Vasc Surg 2000;14:468-472.

23 Robbin ML, Chamberlain NE, Lockhart ME, Gallichio MH, Young CJ, Deierhoi MH, Allon M: Hemodialysis arteriovenous fistula maturity: US evaluation. Radiology 2002;225:5964. 
24 Corpataux JM, Haesler E, Silacci P, Ris HB, Hayoz D: Low-pressure environment and remodelling of the forearm vein in Brescia-Cimino haemodialysis access. Nephrol Dial Transplant 2002;17:1057-1062.

-25 Wong V, How TV, Ward R, Taylor J, Selvakumar S, Bakran A: Input impedance of radiocephalic arteriovenous fistulae for haemodialysis access: its value in predicting early failure. Physiol Meas 1994;15:469-480.

- 26 Tordoir JH, Rooyens P, Dammers R, van der Sande FM, de Haan M, Yo TI: Prospective evaluation of failure modes in autogenous radiocephalic wrist access for haemodialysis. Nephrol Dial Transplant 2003;18:378-383.

27 Yerdel MA, Kesenci M, Yazicioglu KM Doseyen Z, Turkcapar AG, Anadol E: Effect of haemodynamic variables on surgically created arteriovenous fistula flow. Nephrol Dial Transplant 1997;12:1684-1688.

$\checkmark 28$ Lin SL, Huang CH, Chen HS, Hsu WA, Yen CJ, Yen TS: Effects of age and diabetes on blood flow rate and primary outcome of newly created hemodialysis arteriovenous fistulas. Am J Nephrol 1998; 18:96-100.

29 Lin SL, Chen HS, Huang CH, Yen TS: Predicting the outcome of hemodialysis arteriovenous fistulae using duplex ultrasonography. J Formos Med Assoc 1997;96:864-868.
30 Wong V, Ward R, Taylor J, Selvakumar S, How TV, Bakran A: Factors associated with early failure of arteriovenous fistulae for haemodialysis access. Eur J Vasc Endovasc Surg 1996;12:207-213.

31 Beathard GA, Arnold P, Jackson J, Litchfield T, Physician Operators Forum of RMS Lifeline: Aggressive treatment of early fistula failure. Kidney Int 2003;64:1487-1494.

32 Faiyaz R, Abreo K, Zaman F, Pervez A, Zibari G, Work J: Salvage of poorly developed arteriovenous fistulae with percutaneous ligation of accessory veins. Am J Kidney Dis 2002;39: 824-827.

-33 Beathard GA, Litchfield T, Physician Operators Forum of RMS Lifeline: Effectiveness and safety of dialysis vascular access procedures performed by interventional nephrologists. Kidney Int 2004;66:1622-1632.

34 White GH: Planning and patient assessment for vascular access surgery; in Wilson SE (ed): Vascular Access Principles and Practice. St Louis, Mosby Year Book, 1996, pp 611.

35 Turmel-Rodrigues L: Declotting a thrombosed Brescia-Cimino fistula by manual catheter-directed aspiration of the thrombus. Cardiovasc Intervent Radiol 2005;28:10-16.
36 Turmel-Rodrigues L, Pengloan J, Rodrigue H, Brillet G, Lataste A, Pierre D, Jourdan JL, Blanchard D: Treatment of failed native arteriovenous fistulae for hemodialysis by interventional radiology. Kidney Int 2000;57: 1124-1140.

37 Manninen HI, Kaukanen ET, Ikaheimo R, Karhapaa P, Lahtinen T, Matsi P, Lampainen E: Brachial arterial access: endovascular treatment of failing Brescia-Cimino hemodialysis fistulas - Initial success and long-term results. Radiology 2001;218:711-718.

38 Schon D, Mishler R: Pharmacomechanical thrombolysis of natural vein fistulas: reduced dose of TPA and long-term follow-up. Semin Dial 2003;16:272-275.

39 Kumpe DA: Treatment of failing and failed hemodialysis access sites: comparison of surgical treatment with thrombolysis/angioplasty. Semin Vasc Surg 1992;5:118-127.

40 Fan PY, Schwab SJ: Vascular access: concepts for the 1990s. J Am Soc Nephrol 1992;3:111.

41 Marston WA, Criado E, Jaques PF, et al: Prospective randomized comparison of surgical versus endovascular management of thrombosed dialysis access grafts. J Vasc Surg 1997; 26:373-381. 